\title{
College Students' Perceptions of Intelligent Design
}

\author{
Craig Tollini $\cdot$ Jess White
}

Published online: 30 September 2010

(C) Springer Science+Business Media, LLC 2010

\begin{abstract}
While numerous studies address college students' (typically biology majors) perceptions of evolution, research on how students from a range of majors view intelligent design (ID) has not been conducted. In this study, a survey was administered to 692 students, only $2.2 \%$ of whom were biology majors, at a medium-sized Midwestern university. The data from this survey were analyzed to answer the following two research questions: (1) To what extent do college students believe ID is an alternative to, or a better explanation than, evolution? and (2) To what extent do college students believe ID represents a form of creationism? In addition to discussing the results of our analyses, we also provide possible implications of our findings for researchers and educators.
\end{abstract}

Keywords College students · Intelligent design ·

Evolution $\cdot$ Perceptions

\section{Introduction}

While there have been numerous studies that address college students' attitudes toward evolution (Bishop and Anderson 1990; Brem et al. 2003; Fuerst 1984; Grose and Simpson 1982; Ingram and Nelson 2006; Johnson and Peeples 1987; Moore et al. 2006; Robbins and Roy 2007; Sinclair and Baldwin 1995; Sinclair et al. 1997), we were unable to locate any studies that specifically address their attitudes toward the concept of "intelligent design" (ID).

C. Tollini $(\square) \cdot$ J. White

Department of Sociology and Anthropology,

Western Illinois University,

404 Morgan Hall,

Macomb, IL 61455, USA

e-mail: CD-Tollini@wiu.edu
The central premise of ID is that the complexity of organisms and the number and variety of species that exist on Earth can be better explained by the intercession of an unnamed intelligent cause than by the undirected process of natural selection (American Association for the Advancement of Science; Davis and Kenyon 1993; Discovery 2008; International Society for Complexity and Information 2008; Scott 2004). Although ID was not a product of the twenty-first century, it did leap onto the public stage in 2005. During this year, the Kansas State Board of Education adopted standards encouraging the consideration of alternatives to evolution, including ID, in the public school science curriculum (Slevin 2005; Wilgoren 2006). It was also in 2005 that the school board in Dover, PA, was forced to overturn a policy in which a statement that introduced ID as an alternative to evolution was read to high school students prior to material pertaining to evolution (Gallagher and Hirschkorn 2005; Goodstein 2005; Humes 2007; Weinstein 2005).

While the amount of media attention has dropped after the verdict of the Dover trial, ID has continued to appear in the popular and academic press (Apple 2008; Beil 2008; Binder 2007; Burtt 2008; Covaleskie 2008; Dean 2007; Johnson 2006; Martin et al. 2006). Along with this press coverage, several organizations (e.g., the Discovery Institute; the Intelligent Design and Evolution Awareness Center; and the International Society for Complexity, Information, and Design) are currently working to promote ID's inclusion in both research agendas and science education, while all professional scientific societies and organizations (e.g., the American Association for the Advancement of Science, the National Association of Biology Teachers, and the National Center for Science Education) have officially voiced opposition to the inclusion of ID in the science curriculum. Furthermore, the legislatures of several states (e.g., Alabama, Iowa, and Oklahoma) have recently introduced 
bills mandating that alternative theories to evolution, including ID, are presented in science classes (National Center for Science Education 2010). Clearly, the debate regarding evolution and the origin of life has continued.

Given all of these events, we believe it is critical to assess college students' perceptions of ID. As indicated in the introductory paragraph, college students have been the focus of previous research on evolution, undoubtedly not only because they are the new generation of political decision makers but also because they serve as a barometer of the quality of current science education in the U.S. Learning what college students think about ID is important for the same reasons, particularly given the continued presence of ID on the public stage. Ascertaining how students view ID also provides a measure of students' ability to discern the subtle differences presented in the discourse regarding evolution, creationism, and ID. We anticipate these data will inform the curriculum at all levels and influence future academic research on and assessment of scientific literacy. For instance, if students believe that ID is a scientific alternative to evolution because they cannot distinguish between scientific and religious explanations, curricula should be changed to emphasize such topics as the definition of science and its procedural limitations. The findings of this study will also provide some preliminary data regarding how the next generation of young voters and politicians may decide to shape science education policy, whether at the voting booth and school board meetings or through social movements.

In order to address this gap in the literature, we conducted a survey, the results of which will allow us to provide preliminary answers to the following two questions:

1. To what extent do college students view ID as an alternative to, or as a better explanation than, evolution? ID advocates argue that ID is scientific and, therefore, a viable, if not superior, alternative to evolution because it enables researchers to incorporate the design apparent in living organisms (Discovery 2008; Humes 2007; Intelligent Design 2008; International Society for Complexity and Information 2008). Opponents of ID contend that it does not represent an alternative to evolution, and therefore could not be superior to evolution, because it uses non-empirical evidence (American Association for the Advancement of Science 2008; Covaleskie 2008; Humes 2007; National Center for Science Education 2008a, 2008b). The survey we conducted will provide some information regarding how students believe ID compares to evolution, in part to determine the extent to which students agree with the proponents or opponents of ID.

2. To what extent do college students view ID as a variation of creationism? Although supporters of ID clearly and consistently state that it is not a religious concept, many prominent ID supporters state that they personally believe the intelligent designer is God (DeWolf et al. 2006; Discovery 2008; Humes 2007; Intelligent Design 2008; International Society for Complexity and Information 2008). Moreover, conservative Christians have constituted the majority of the supporters of the Dover policy, the revised education standards in Kansas, and other courses and policies that promote ID (Forrest and Gross 2004; Humes 2007). Citing the religious convictions of ID's supporters, as well as the central role of a potentially supernatural designer in ID, opponents of ID often label it as a revised or disguised version of creationism (Apple 2008; Binder 2007; DeWolf et al. 2006; Forrest and Gross 2004; Humes 2007; Johnson 2006; National Center for Science Education 2008a, 2008b; Peterson 2002). In this study, we present information regarding which of these perspectives students hold.

\section{Material and Methods}

Data Collection and Sample This project was conducted on the main campus of a medium-sized, Midwestern public university. Fifty courses that had at least 25 enrolled students were randomly selected. The faculty members assigned to these courses received letters and e-mail messages describing the project and asking for permission to administer the survey during a class meeting. Faculty members who did not respond within a week received a reminder e-mail.

Of the 35 faculty members who responded, $23(65.7 \%$ of those who responded and $46.0 \%$ of all 50 faculty members) gave permission for the survey to be administered in their classes. This sample of courses included both lower- and upperdivision courses and courses from a range of departments, including accounting, African American studies, broadcasting, education, geology, mathematics, family and consumer sciences, history, law enforcement, and sociology. In sharp contrast, the majority of the researchers who surveyed college students about their views of evolution drew their samples from one or more courses in the biological sciences (Bishop and Anderson 1990; Demastes et al. 1995; Fuerst 1984; Grose and Simpson 1982; Ingram and Nelson 2006; Johnson and Peeples 1987; Moore et al. 2006; Robbins and Roy 2007; Sinclair et al. 1997; Wilson 2001). We included a broader range of courses in order to better reflect the diversity of the student population, which will impact the generalizability of our findings. Obtaining the views of a broader range of students is also important because students may be exposed to ID and evolution in non-biology classes (e.g., anthropology), 
and all college students, regardless of major, can support or oppose policies regarding the teaching of evolution and ID as voters and community members.

The surveys were administered over a two-week period. Data from the surveys were entered into statistical package for the social sciences (SPSS), and 70 randomly selected surveys were checked for errors. Although a few errors were found (and subsequently corrected), there were no patterns in these errors. Some of the surveys were removed from the sample because the respondent (1) was under 18 years old, (2) was a faculty member or graduate student, (3) was an international student, or (4) had only answered a few questions. The final sample contained 692 surveys, which was $64.2 \%$ of the students enrolled in the classes in which the survey was administered and $30.3 \%$ of the students enrolled in all 50 classes.

As Table 1 illustrates, the sample largely reflected the university population. In fact, the only substantive and significant difference between the sample and the university population was that the sample had more sophomores than the population $(z=4.04, p<0.001)$. Additional evidence that the sample represents the population is that the respondents had a wide range of majors. The sample was comprised of almost entirely non-biology majors; only 15 respondents $(2.2 \%)$ indicated they were biology majors. Although all of the students were from a single university, we argue that our findings have some degree of generalizability to a broader cross-section of American students for two factors: (1) the occurrence of key events in the development of the ID debate in geographically close states (e.g., Kansas and Ohio) and (2) the likelihood that regional, public universities are likely to draw students that mirror the larger American college student population as a whole. Furthermore, previous research on students' perceptions and knowledge of evolution has utilized and inferred broader trends from samples originating from a single, Midwestern university (Fuerst 1984; Ingram and Nelson 2006; Moore et al. 2006; Sinatra et al. 2003).

Measures The survey was designed by the authors in consultation with other faculty members (from the departments of biological sciences and philosophy and religious studies) at our institution. It consisted of two, double-sided pages, and most respondents completed it within 1015 minutes. The entire survey is included in the appendix; only the variables used in our analysis are discussed in this section.

ID Variables Three questions in the survey addressed respondents' attitudes toward ID. All had the same response options: "strongly agree," "agree," "neither agree nor disagree," "disagree," "strongly disagree," and "unsure or don't know." The first two survey questions dealt with the relationship between evolution and ID; these questions asked respondents to what extent they agreed that ID (1) is an alternative to evolution and (2) provides a better explanation than evolution. These questions were designed to address our first research question. These two questions had a Cronbach's alpha of 0.776 , so we combined them in our bivariate analyses. More specifically, we calculated a factor score using principal components analysis with varimax rotation. Only the two ID questions were included in the analysis, and they both had a factor loading of 0.904 on the single dimension produced by the analysis. Respondents with higher values for this factor score are more likely to disagree with the statements that ID is a viable or superior alternative to evolution than respondents with lower factor scores. The third survey question regarding respondents' perceptions of ID asked respondents to what extent they agreed that ID is creationism; this question was included to address our second research question.

Additional Variables We included 11 additional questions in order to determine if respondents with certain traits were more or less likely to have a particular perception of ID. We believed six of these questions would correlate with the respondents' views of the relationship between ID and evolution.

Three of these survey questions directly addressed the respondents' views of evolution. These questions asked respondents to what extent they agreed that evolution is (1) a guess because it is a theory, (2) a fact, and (3) completely supported by the evidence. These questions had the same response options as the ID questions, and they had a Cronbach's alpha of 0.718 . Given this statistic, we calculated a factor score for this set of variables as well. All three items loaded on the same dimension; the first had a factor loading of 0.636 , while the other two had loadings of 0.885 and 0.874 , respectively. Respondents with higher values for this factor score had a more negative view of evolution (or saw evolution as less supported) than respondents with lower factor scores. We anticipated that respondents who agreed that evolution is a guess would be more likely to agree that ID is a viable or superior alternative to evolution, while respondents who agreed that evolution is fact and is completely supported by the evidence would be less likely to agree with this perception of ID. We expected to find these relationships for two reasons. First, the opponents of ID tend to describe evolution as well supported, while ID's proponents are more likely to discuss limitations of evolution and to describe it as a guess or supposition because it is "just a theory" (Davis and Kenyon 1993; Humes 2007; Intelligent Design 2008; Johnson 2006; Scott 2004). Second, some of 
Table 1 Percentages of selected demographic traits in the sample and population
Population data, which were provided by the university, are for the same semester the survey was conducted. These percentages were calculated after the respondents who did not answer the question or who selected "unsure/don't know" were removed. Only one question had a large percent of respondents who selected this category; $20.2 \%$ selected "unsure/don't know" when asked about their political ideology

${ }^{\mathrm{a}}$ The population used to calculate these percentages includes students on the other campus of the university, as well as in its extension programs

${ }^{\mathrm{b}}$ The categories used for the population data did not match the categories in the survey

\begin{tabular}{|c|c|c|}
\hline & $\%$ of Sample & $\%$ of Population \\
\hline \multicolumn{3}{|l|}{ Rank } \\
\hline Freshman & 11.2 & 28.5 \\
\hline Sophomore & 30.0 & 19.0 \\
\hline Junior & 29.9 & 24.2 \\
\hline Senior & 28.8 & 28.3 \\
\hline \multicolumn{3}{|l|}{ Sex } \\
\hline Male & 52.2 & 54.1 \\
\hline Female & 47.8 & 45.9 \\
\hline \multicolumn{3}{|l|}{$\operatorname{Race}^{\mathrm{a}, \mathrm{b}}$} \\
\hline White or Caucasian & 86.4 & 79.4 \\
\hline Black, African, or African American & 5.0 & 7.1 \\
\hline Hispanic, Latino/a, Latin American, or South American & 3.8 & 4.6 \\
\hline Asian, Asian American, or Pacific Islander & 1.4 & 1.2 \\
\hline Native American or Alaskan Native & 0.2 & 0.5 \\
\hline North African, Middle Eastern, or Indian & 0.2 & \\
\hline Multiracial & 3.2 & - \\
\hline \multicolumn{3}{|l|}{ Religious affiliation } \\
\hline Protestant & 29.5 & - \\
\hline Catholic & 41.9 & - \\
\hline Unidentified/other type of Christian & 7.0 & - \\
\hline Other & 2.9 & - \\
\hline None & 18.8 & - \\
\hline \multicolumn{3}{|l|}{ Type of high school attended } \\
\hline Public & 85.8 & - \\
\hline Private, not religiously affiliated & 0.3 & - \\
\hline Private, religiously affiliated & 11.1 & - \\
\hline More than one type & 2.7 & - \\
\hline \multicolumn{3}{|l|}{ Type of community in which $\mathrm{R}$ grew up } \\
\hline Rural & 33.2 & - \\
\hline Suburban & 47.9 & - \\
\hline Urban & 14.1 & - \\
\hline More than one type & 4.8 & - \\
\hline \multicolumn{3}{|l|}{ Political ideology } \\
\hline Very liberal & 7.5 & - \\
\hline Liberal & 30.4 & - \\
\hline Moderate or "middle of the road" & 32.0 & - \\
\hline Conservative & 25.7 & - \\
\hline Very conservative & 4.5 & - \\
\hline
\end{tabular}

the research on the "nature of science" indicates that people's view of evolution and science (i.e., their understanding of what a scientific theory is) impacted their acceptance of evolution (Cavallo and McCall 2008; Hokayem and Boujaoude 2008; Lombrozo et al. 2008). It is reasonable to expect that a similar relationship might exist regarding ID so that people who view evolution as "strong" and supported would be less likely to view ID as a viable or superior alternative than those who view evolution as "weak" or unsupported.
The other three survey questions that we assumed would correlate with the responses to the questions regarding the relationship between ID and evolution all addressed respondents' exposure to information about evolution. The first of these questions asked respondents how often they watched documentaries or television programs about evolution. Given the wording of the question, these programs may or may not be scientific and could be intended for any type of audience. The second and third questions asked respondents how much they had learned 
about evolution in high school and college, respectively. The response options for the question regarding media exposure were "very," "somewhat," "not very," "never," and "unsure"; the response options for the educational exposure questions were "very," "somewhat," "not very," "nothing," and "unsure." These questions had a Cronbach's alpha of 0.526 (and 0.422 for the two questions regarding education), so we had to include them individually in our analyses. We anticipated that respondents with more exposure to evolution (whether via the media or education) would be less likely than those with less exposure to agree that ID is an alternative to or a better explanation than evolution because we assumed that the content of these programs and courses would most likely provide a "strong" view of evolution (as described above). We believe that this relationship will exist in part because some previous researchers have found that students' exposure to evolution and science in the classroom impacts their views and acceptance of evolution and science (Fuerst 1984; Gogolin and Swartz 1992; Ingram and Nelson 2006; Moore and Cotner 2009).

We included five additional survey questions in our analyses because each question could potentially correlate with the three ID questions, though we did not have any specific expectations regarding these potential correlations. While all of these variables arguably have an empirically supported relationship with a person's perceptions of ID, creationism, and/or evolution, there is no evidence of a direct correlation with people's perceptions of the relationships between ID and either evolution or creationism. We included the respondents' class rank because their perceptions of ID, evolution, and creationism may all change as they take more classes and gain more experiences and skills; previous research indicates that class rank impacts students' acceptance of evolution (Paz-y-Mino and Espinosa 2009b). Another question that we included asked participants to describe their political ideology; we included this question because conservatives tend to have more support for creationism and ID and to be more critical of evolution (Forrest and Gross 2004; Humes 2007; Johnson 2006; Peterson 2002). We also included the question that asked respondents whether they grew up in a rural, suburban, or urban area (after excluding the participants who had lived in more than one type of area) because the cases involving ID occurred in rural areas and people in rural areas tend to have less support for evolution, more support for creationism, and to be more conservative and religious than people in urban areas (Binder 2007; Humes 2007; Johnson 2006; Peterson 2002; Scott 2004). Another question in the survey asked respondents what type of high school they attended. The categories that were selected by enough respondents to allow for a meaningful comparison were public school and religiously affiliated private school.
Given the religious opposition to evolution and support for ID noted above and the possibility that creationism could be presented (and presented as a science) in religiously affiliated schools (Binder 2007; Forrest and Gross 2004; Johnson 2006; Peterson 2002; Scott 2004), we decided to include this variable. Finally, we included the question that asked respondents to what extent they agree that God works through evolution. We selected this question because it could be seen as an alternative definition of ID, albeit one with a more explicitly creationist wording. Given this similarity, we were interested to see how respondents' views of this question related to their responses to all three ID questions.

We could have included two additional questions from the survey (religious affiliation and major) in our analyses, but we decided against doing so because of problems with the questions and/or sample. Religious affiliation might correlate with respondents' views of ID because evolution is strongly contested by Protestants, especially evangelicals (Scott 2004). Unfortunately, only three categories ("Protestant," "Catholic," and "none") were selected by enough respondents to conduct analyses, and these categories were too broad to be useful (i.e., "none" could include both atheists and devout believers who are not formally affiliated with any religious organization and "Protestant" could include members of both evangelical and non-evangelical denominations). Comparing students who are biology majors to non-biology majors would also be a useful analysis because students' views of ID and evolution is likely to vary based on the material they were exposed to in their coursework. This relationship is supported by the literature cited during the discussion of the "exposure to evolution" variables, and there are other studies that found students with different majors view evolution and science differently (Gogolin and Swartz 1992; Paz-y-Mino and Espinosa 2009a; Wilson 2001). Unfortunately, as noted earlier, the sample was comprised almost entirely of nonbiology majors, so these analyses could not be conducted.

\section{Data Analysis}

Attitudes Toward ID Table 2 provides the frequency distributions of the three ID questions. For each question, a substantial minority of the respondents (between approximately one fourth and one third) selected "don't know/unsure." Furthermore, roughly half of the respondents who selected a category other than "don't know/unsure" selected "neither agree nor disagree" for each of the questions. The remaining responses to the statement that ID provides a better explanation than evolution were roughly split between agree $(22.4 \%)$ and disagree $(26.2 \%)$; students 


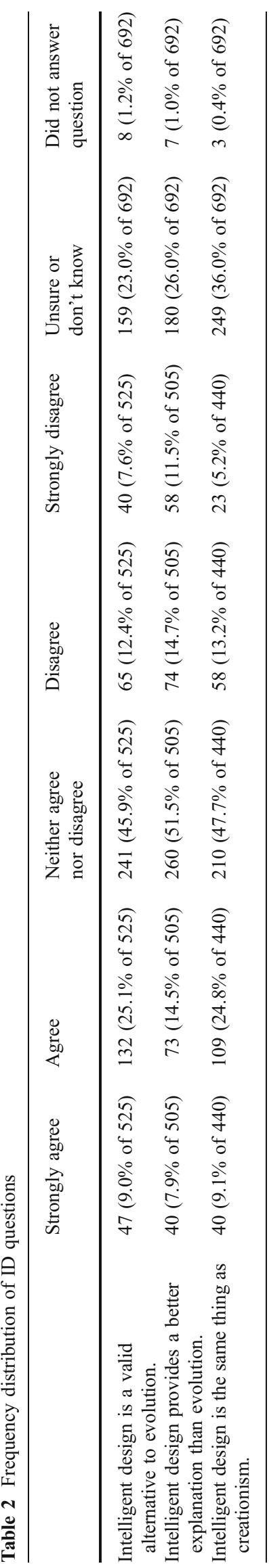

were somewhat more likely to agree than to disagree to the other two statements.

As noted above, the two questions regarding the relationship between ID and evolution were combined into an index, more specifically a factor score. This index, which we have labeled the "ID and Evolution Factor Score," was not correlated with the question regarding the relationship between ID and creationism (see Table 3; due to the number of analyses conducted, significance was determined using Bonferroni's correction).

Correlations with Other Variables In order to determine if certain types of students were more or less likely to have a particular view of ID, we calculated additional correlation coefficients, as well as one $t$ test of the equality of means (see Table 3). The question stating that ID is a form of creationism was not significantly correlated with any of the 11 variables.

The ID and Evolution Factor Score was only significantly correlated with three variables. The first was the index of the questions regarding respondents' views of evolution and science, which we have labeled the "Views of Evolution Factor Score." This variable had a negative relationship with the ID and Evolution Factor Score; respondents who viewed evolution more positively were more likely to not view ID as an alternative or superior to evolution than respondents who had a more negative perception of evolution. The second variable that had a significant relationship with the ID and Evolution Factor Score was the question regarding how often respondents watched programs about evolution; respondents who watched this type of programming more often were more likely to disagree that ID is a viable or superior alternative to evolution than respondents who never watched such programs. The third and final variable was political ideology; respondents who identified as liberal were more likely to disagree that ID is a viable or superior alternative to evolution than conservatives, who were more likely to agree.

Analysis of Respondents Who Did and Did Not Select "Don't Know" for the ID Questions As noted above, a sizable minority of the respondents selected "don't know/ unsure" for each of the ID questions. Given these results, we decided to investigate if and how students' responses to the other variables included in the previous analyses correlated with their decision to select "don't know" for the ID questions. To conduct these analyses, we transformed the question that asked respondents if they agreed that ID is a form of creationism so it was dichotomous, with one category for "selected don't know" and the other for "did not select don't know." We performed a similar transformation on the ID and Evolution Factor Score. All respondents with a factor 
Table 3 Correlations of variables

\begin{tabular}{lll}
\hline Variables & ID and evolution factor score & ID is creationism \\
\hline ID is creationism & Gamma $=0.168, p=0.008$ & - \\
Views of evolution factor score & Pearson's $\mathbf{r}=\mathbf{- 0 . 3 8 2}, \mathbf{p}=\mathbf{0 . 0 0 0}$ & - \\
How often watched programs about evolution & Gamma $=-\mathbf{0 . 1 8 9}, \mathbf{p}=\mathbf{0 . 0 0 0}$ & - \\
How much learned about evolution in high school & Gamma $=-0.041, p=0.456$ & - \\
How much learned about evolution in college & Gamma $=-0.051, p=0.177$ & Gamma $=0.051, p=0.455$ \\
God works through evolution & Gamma $=0.145, p=0.009$ & Gamma $=-0.165, p=0.016$ \\
Attended public or religious private school & $t$ test $0.787, d f 460, p=0.432$ & Gamma $=0.049, p=0.406$ \\
Urban/suburban/rural & Gamma $=0.006, p=0.912$ & Gamma $=-0.045, p=0.499$ \\
Class rank & Gamma $=0.015, p=0.750$ & $\mathbf{G a m m a}=-\mathbf{0 . 2 0 7}, \mathbf{p}=\mathbf{0 . 0 0 0}$
\end{tabular}

Significant correlations are in bold; alpha level based on Bonferroni's correction is $0.0033(0.05 / 15)$

Correlations calculated based on Yate's correction for chi-squared are italicized

score were coded as "did not select don't know," while all respondents for whom a factor score could not be calculated because they had selected "don't know" for at least one question were coded as "selected don't know."

The transformed version of the question stating that ID is a form of creationism was significantly correlated with the transformed version of the ID and Evolution Factor Score (see Table 4); respondents were likely to select "don't know" for either both or neither variable. The transformed version of the question stating that ID is a form of creationism did not have any significant correlations with any of the other variables, however.

In addition, the transformed version of the ID and Evolution Factor Score had significant correlations with only two other variables. The first was the question that asked respondents how often they viewed programs about evolution; the percentage of respondents who selected "don't know" decreased as the amount of viewing increased. The second variable was the question that asked respondents how much they learned about evolution in college; respondents who indicated they learned nothing about evolution in college were more likely to select "unsure," though so were respondents who selected "very much."

\section{Discussion and Conclusions}

College Students' Views of ID The first research question of this project deals with students' perceptions of the relationship between ID and evolution, while the second deals with their perceptions of the relationship between ID and creationism. Our findings indicate that a good portion of the students surveyed for this study did not know enough about ID to respond to any of the ID questions and that roughly half of those who did respond took a neutral position, perhaps because they did not have enough

Table 4 Correlations of variables when ID variables are recoded to "select don't know" and "did not select don't know"

\begin{tabular}{lll}
\hline Variables & ID and evolution factor score & ID is creationism \\
\hline ID is creationism & $\mathbf{P h i}=\mathbf{0 . 7 2 9}, \boldsymbol{p}=\mathbf{0 . 0 0 0}$ & - \\
Views of evolution factor score & $t 1.12, d f 603, p=0.261$ & - \\
How often watch programs about evolution & Cramer's $\boldsymbol{V}=\mathbf{0 . 1 5 3}, \boldsymbol{p}=\mathbf{0 . 0 0 1}$ & - \\
How much learned about evolution in high school & Cramer's $V=0.127, p=0.015$ & - \\
How much learned about evolution in college & Cramer's $\boldsymbol{V}=\mathbf{0 . 1 5 4}, \boldsymbol{p}=\mathbf{0 . 0 0 1}$ & Cramer's $V=0.046, p=0.872$ \\
God works through evolution & Cramer's $V=0.052, p=0.813$ & Phi $=0.026, p=0.507$ \\
Attended public or religious private school & Phi $=0.031, p=0.425$ & Cramer's $V=0.061, p=0.315$ \\
Urban/Suburban/Rural & Cramer's $V=0.074, p=0.190$ & Cramer's $V=0.112, p=0.040$ \\
Class rank & Cramer's $V=0.098, p=0.097$ & Cramer's $V=0.147, p=0.031$
\end{tabular}

Significant correlations are in bold; alpha level based on Bonferroni's correction is $0.0033(0.05 / 15)$

Correlations calculated based on Yate's correction for chi-squared are italicized 
information about ID. Furthermore, a roughly equal percentage of the students in our sample agreed or disagreed with each of the three statements about ID.

This last finding provides evidence that our respondents, like the general public, are divided in their views of ID. Some respondents agree with the opponents of ID, while others agree with its supporters, perhaps because members of each group have been able to get their message to a portion of our sample. Given this divide in opinion, some college students may support certain policies regarding ID, while others may oppose these same policies. In addition, faculty members may encounter students who have markedly different views of ID and its place in the classroom, which may lead to debate and disagreement. It may not be likely that a large number of students will be actively involved in any protests or counter-protests or create problems for educators in regard to ID, however, because the majority of the students in our sample appear to be ignorant of or indifferent to this topic. If the supporters and opponents of ID have worked to actively engage students and to "educate" them about ID, it would seem that their attempts have largely failed.

Another noteworthy finding of this preliminary study is that while the students we surveyed were likely to select "unsure" for the ID question regarding creationism and the factor score based on the questions regarding ID and evolution, the responses to questions regarding ID and creationism were not significantly correlated with the ID and Evolution Factor Score. Given the general discussion of the relationship between evolution and creationism in U.S. society, as well as the discourse generated by the supporters and opponents of ID, one would expect people who reject ID as a viable or superior alternative to evolution would also label it as creationism. The findings did not support this, however. As a result, even the students in our sample who shared one belief with the proponents or opponents of ID would not necessarily share all of the views of this group. As noted before, this may indicate that any attempts by either group to convey their views to college students have not been fully successful. At the very least, the respondents did not have the same overall perception of ID that its supporters and opponents have. This finding also indicates that there is likely to be continued conflict in regards to ID, even between those who share one view of it. Thus, instructors may need to keep in mind that students may have different views of these concepts.

A possible explanation for this finding is that some students may view creationism as scientific, a claim made by some creationists (Center for Scientific Creation 2009; Institute for Creation Research 2009; Southern Baptist 1982). Similarly, some respondents may consider science and religion to be complementary approaches or otherwise fail to differentiate between religious and scientific explanations. As a result, some students could view ID as both creationism and as an alternative to evolution, while other students would not. This variation may be the source of the non-significant findings. The relationship between ID, evolution, and creationism appears to be more complex than that promoted in the rhetoric of ID's supporters and opponents. More research on these relationships is clearly needed in order to verify and better explain our findings.

Variation in Views of ID Our analyses revealed that in the few cases where the students in our sample who had different traits varied in their views of ID, these differences met our expectations. The respondents who had a weaker or more negative view of evolution were more likely than respondents with a stronger or more positive perception of evolution to view ID as a viable and possibly superior alternative to evolution. Furthermore, respondents who never watched programs about evolution (compared to those who often watched such programs) were more likely to view ID as a viable or superior alternative to evolution. These findings support our expectations that students who viewed evolution as "strong" and well supported would be less likely to view ID as a superior alternative to evolution than those who held a "weaker" view of evolution. Our results also supported our claim regarding media exposure, and they further indicate that most programming about evolution provides a "strong" view of the theory (or at least a perspective that denigrates ID). Another implication of this finding is that faculty members, as well as supporters and opponents of ID, may be well served to utilize television programming and documentaries in order to convey their message to college students. Finally, respondents who identified as conservative were more likely than those who identified as liberal to view ID as a viable and superior alternative to evolution. This finding is sensible given the previous research on the relationships between political ideology and either evolution or ID, and it indicates that ideology is a salient factor when dealing with these specific aspects of ID. Therefore, researchers should continue to include ideology in their analyses, and educators may benefit from utilizing the results of this research if certain students raise objections to how evolution and/or ID are presented in the classroom.

When the demographic and evolution variables were correlated with the transformed versions of the ID variables (those that had one option for "selected unsure" and another for "not select unsure"), there were only two significant findings. Respondents who often watched programs and documentaries about evolution were less likely to select "unsure" to at least one of the questions regarding ID and evolution than respondents who never watched such media. These relationships match our expectations, but the other 
one does not. The percentage of the students in our sample who selected "don't know" for at least one of the questions regarding ID and evolution decreased and then increased as the coverage of evolution in their college courses increased. This pattern may occur because students who have had more coursework related to evolution still have not learned about ID in their classes and/or may be aware of the nuances and limitations of the theory, which could lead them to be less certain regarding how evolution and ID relate to each other. Further research should address this potential issue, which may have serious implications for faculty members.

Unanticipated findings like these are noteworthy because they indicate that our understanding of ID, as well as evolution and creationism, is most likely partial, if not incorrect. The same can also be said for the non-significant results. The majority of the correlations were not significant. As indicated above, nearly all of the relationships involving the transformed ID questions were not significant, which indicates that very few of the included factors are related to respondents' admitted ignorance of ID. All of these results indicate that several variables are not correlated with the surveyed students' responses to one or more of the ID questions, even though we would expect to see some type of relationship.

One of these variables is education. One possible reason that the education variables were not significantly correlated with all of the ID questions is that ID is not addressed in a similar way across various classrooms. In addition, students may rely on other sources of information when they construct their opinions of ID; the observed relationship between media exposure and the ID questions indicates that media is one likely source. Similar arguments may explain why the type of high school the students attended and the type of area where they grew up had no relationship with the students' answers to the original or transformed ID variables.

Different arguments may be able to address the lack of a significant relationship between political ideology and the question regarding ID as creationism. This finding may be due to the wide range of viewpoints that could still be contained under the umbrella terms of "liberal," "moderate," and "conservative."

We are unable to provide possible explanations for the other variables that do not have significant correlations. Future research should address these variables, as well as test and explore the arguments made above. One variable to address would be class rank. Why is it that seniors are no different from freshmen? Do these findings mean that students' views and knowledge of ID are unlikely to change with time? In addition, why is it that the responses to the question regarding the belief that God works through evolution were not related to any of the ID variables?
We also suggest that future research should sample from multiple institutions and collect data from enough biology majors to compare them to non-majors. Any future study should also include measures of additional variables, especially participants' understanding of the "nature of science," and additional measures of the complex variables addressed by our research. As our data show, the variety of factors that may be influencing students' understanding of ID should be further explored and potential explanations for any confirmed patterns offered. Our data suggest that there is not one single factor or aspect of ID that would necessarily be "logical" for instructors to address; instead, curriculum should address the complexity of factors that influence any issue of evolution or scientific literacy.

Acknowledgments The authors would like to thank the following for their support in this project and for insightful discussions and comments: the College of Arts and Sciences (WIU); the Department of Sociology and Anthropology (WIU); Dr. Matthew Bonnan, Department of Biological Sciences (WIU); Dr. Christopher Pynes, Department of Philosophy and Religious Studies (WIU).

\section{References}

American Association for the Advancement of Science. 2008. Questions and Answers on Evolution. http://www.aaas.org/ news/press_room/evolution/pdf/QA_Evolution.pdf. Accessed 19 August 2008.

Apple M. Evolution versus creationism in education. Educ Policy. 2008;22(2):327-35.

Beil L. 2008. Opponents of evolution are adopting new strategy. New York Times A14; June 4.

Binder A. Gathering intelligence on intelligent design: where did it come from, where is it going, and how should progressives manage it? Am J Educ. 2007;113:549-76.

Bishop B, Anderson C. Student conceptions of natural selection and its role in evolution. J Res Sci Teach. 1990;27(5):415-27.

Brem S, Ranney M, Schindel J. Perceived consequences of evolution: college students perceive negative personal and social impact in evolutionary theory. Sci Educ. 2003;87:181-206.

Burtt B. Deliberative democracy and intelligent design: the ruling in "Kitzmiller v. Dover.". Theory Res Educ. 2008;6(1):95-105.

Cavallo A, McCall D. Seeing may not mean believing: examining students' understandings and beliefs in evolution. Am Biol Teach. 2008;70(9):522-30.

Center for Scientific Creation. 2009. In the beginning: compelling evidence for creation and the flood. http://www.creationscience. com/onlinebook/index.html. Accessed 11 August 2009.

Covaleskie J. Three why's: religion and science in school. Educ Stud. 2008;43(1):7-16.

Davis P, Kenyon D. Of pandas and people: the central question of biological origins. 2nd ed. Dallas: Haughton Publishing; 1993.

Dean C. 2007. Battlefield report from the evolution war. New York Times B30; November 11.

Demastes S, Good R, Peebles P. Students' conceptual ecologies and the process of conceptual change in evolution. Sci Educ. 1995;79 (6):637-66. 
DeWolf D, West J, Luskin C, Witt J. Traipsing into evolution: intelligent design and the Kitzmiller $v s$. Dover Decision. Discovery Institute, Seattle, WA; 2006.

Discovery Institute. 2008. What is intelligent design? http:/www. intelligentdesign.org/. Accessed 19 August 2008.

Forrest B, Gross P. Creationism's Trojan horse: the wedge of intelligent design. 2nd ed. New York: Oxford University Press; 2004.

Fuerst P. University student understanding of evolutionary biology's place in the creation/evolution controversy. Ohio $\mathrm{J}$ of Sci. 1984;84(5):218-28.

Gallagher D, Hirschkorn P. 2008. Judge rules against "intelligent design" in science class. http://cnn.com/2005/LAW/12/20/intelligent.design/ index.html. Accessed 19 August 2008.

Gogolin L, Swartz F. A quantitative and qualitative inquiry into the attitudes toward science of nonscience college students. J Res Sci Teach. 1992;29(5):487-504.

Goodstein L. 2005. Issuing rebuke, judge rejects teaching of intelligent design. New York Times A1; December 21.

Grose E, Simpson R. Attitudes of introductory college biology students toward evolution. J Res Sci Teach. 1982;19(1):15-24.

Hokayem H, BouJaoude S. College students' perceptions of the theory of evolution. J Res Sci Teach. 2008;45(4):395-419.

Humes E. Monkey girl: evolution, education, religion, and the battle for America's soul. New York: Ecco; 2007.

Ingram E, Nelson C. Relationship between achievement and students' acceptance of evolution or creation in an upper-level evolution course. J Res Sci Teach. 2006;43(1):7-24.

Institute for Creation Research. 2009. Evidence for creation. http:// www.icr.org/Evidence/. Accessed 11 August 2009.

Intelligent Design Network. 2008. Intelligent design network: seeking objectivity in origins science. http://www.intelligentdesignnet work.org/. Accessed 19 August 2008.

International Society for Complexity, Information, and Design. Intelligent design. http://www.iscid.org/encyclopedia/Intelligent_Design. Accessed 19 August 2008.

Johnson V. A contemporary controversy in American education: including intelligent design in the science curriculum. Educ Forum. 2006;70(3):222-36.

Johnson R, Peeples E. The role of scientific understanding in college: student acceptance of evolution. Am Biol Teach. 1987;49(2):93-8.

Lombrozo T, Thanukos A, Weisberg M. The importance of understanding the nature of science for accepting evolution. Evolution: Education and Outreach. 2008;1:290-8.

Martin J, Trammell K, Landers D, Valois J, Bailey T. Journalism and the debate over origins: newspaper coverage of intelligent design. Journal of Media and Religion. 2006;5(1):49-61.
Moore R, Cotner S. Educational malpractice: the impact of including creationism in high school biology courses. Evolution: Education and Outreach. 2009;2:95-100.

Moore R, Froehle AM, Kier J, Greenwald B. How biology students in Minnesota view evolution, the teaching of evolution, and the evolution-creationism controversy. Am Biol Teach. 2006;68(5): e35-42 (online)

National Center for Science Education. 2008a. News. http://ncseweb. org/news. Accessed 11 August 2009.

National Center for Science Education. 2008b. Resources. http://www. natcenscied.org/article.asp?category $=8$. Accessed 19 August 2008.

National Center for Science Education. 2010. News. http://ncse.com/ news. Accessed 8 September 2010.

Paz-y-Mino G, Espinosa A. Assessment of biology major's versus nonmajors' views on evolution, creationism, and intelligent design. Evolution: Education and Outreach. 2009a;2:75-83.

Paz-y-Mino G, Espinosa A. Acceptance of evolution increases with student academic level: a comparison between a secular and a religious college. Evolution: Education and Outreach. 2009b;2:655-75.

Peterson G. The intelligent-design movement: science or ideology? Zygon. 2002;37(1):7-23.

Robbins J, Roy P. The natural selection: identifying and correcting nonscience student preconceptions through an inquiry-based, critical approach to evolution. Am Biol Teach. 2007;69(8):460-6.

Scott E. Evolution vs. creationism: an introduction. Berkeley: University of California Press; 2004.

Sinatra G, Southerland S, McConaughy F, Demastes J. Intention and belief in students' understanding and acceptance of biological evolution. J Res Sci Teach. 2003;40(5):510-28.

Sinclair A, Baldwin B. Biology students' beliefs about evolutionary theory and religion. Res Sch. 1995;2(2):31-8.

Sinclair A, Pendarvis M, Baldwin B. The relationship between college zoology students' beliefs about evolutionary theory and religion. J Res Dev Educ. 1997;30(2):118-25.

Slevin P. 2005. Kansas Education Board first to back "intelligent design": schools to teach doubts about evolutionary theory. Washington Post A1; November 9.

Southern Baptist Convention. 1982. Resolution on scientific creationism. http://www.sbc.net/resolutions/amResolution.asp?ID=967. Accessed 11 August 2009.

Weinstein H. 2005. Judge says "intelligent design" is not science: he calls for a school board's effort to teach it as an alternative to evolution unconstitutional. Los Angeles Times A1; December 21.

Wilgoren J.2006. In evolution debate, a counterattack. New York Times A3; January 1.

Wilson J. Pseudoscientific beliefs among college students. Reports of the National Center for Science Education. 2001;21(1-2):9-13. 